\title{
Research on optimization of warehouse layout based on SLP theory-- Take Deppon Express Warehouse for example
}

\author{
Xiaobing $\mathrm{Le}^{1}$, Xueliang Wang ${ }^{2 *}$ and Zhiheng Huang ${ }^{3}$ \\ ${ }^{1}$ Wuzhou University, Wuzhou Guangxi, 543002, China \\ ${ }^{2}$ Wuzhou University, Wuzhou Guangxi, 543002, China \\ ${ }^{3}$ Wuzhou University, Wuzhou Guangxi, 543002, China
}

\begin{abstract}
This paper takes Deppon Express Company as an example to study the optimization of the layout of the store warehouse under the standardized operation mode. First of all, it Analyzes warehouse layout present situation of the express company, and gets the problems of the warehouse layout of the company, for example, the layout of the lack of scientific, as well as part of the operational areas of position arrangement is not reasonable and unreasonable action path which leads to the whole business operation efficiency is low. Finally, thus using SLP to solve those problems, and put forward the company store aisle warehouse layout optimization strategy of management according to the comprehensive relations preliminary to the data warehouse layout optimization figure.
\end{abstract}

\section{INTRODUCTION}

As one of the important links of the circulation of goods in the logistics activities, warehouse is also an important pillar of the logistics link. It plays an important role in the import and export of goods, the storage of goods and the improvement of the transfer rate of goods. On July 2, 2018, the brand name of the company was changed from the original "Deppon Logistics" to "Deppon Express", announcing the formal entry into the large-volume express industry, mainly furniture, home appliances and other large-volume express. With the development of the company, the volume of business also presents an upward trend. Under the circumstances of adding new business background conditions, the layout design of the warehouse should also seamlessly connect with the new business scope, which makes the company face a new round of challenges.

\section{THEORETICAL OVERVIEW}

\subsection{Concept of cargo area layout optimization}

Warehouse layout optimization refers to the overall planning within the scope of the warehouse under the conditions of meeting the company's overall development goal, future development direction and specific business scope, so that the daily production operation and operation process of the warehouse can run smoothly, and the logistics operation elements in the warehouse can be connected organically. At the same time, make full use of the space, planning and design the infrastructure and equipment of the warehouse, and maximize the storage and operation functions of the warehouse $^{[1]}$.

Process of the rolls, such as goods receiving, storage, packaging, outbound, loading activity relationship of the process, and according to the characteristics of inventory, warehouse type, size, operation method, and the surrounding environment, and many other factors in process design, make warehouse work safer, works more smoothly, the goods storage safeguard, conform to the requirements of the company's long-term interests ${ }^{[2]}$.

\subsection{The objective of optimizing the layout of warehouse cargo area}

For different logistics enterprises between their logistics goal is roughly same, its essence is the same: effective management inventory, storage, dispatch of the goods the three links, in the warehouse, under the condition of limited space distribution of limited resources of the rolls and combination, make the rolls of the personnel, equipment and operational efficiency maximization of goods $^{[3]}$. The objectives of warehouse layout optimization can be summarized as follows:

(1) Put the goods in the appropriate position, as far as possible to reduce the number of handling of goods, reduce loading, unloading and handling costs;

(2) Shorten the operation cycle, reasonably plan the operation process and operation path;

(3) Reduce cargo damage, reduce storage costs, and improve customer satisfaction;

(4) More efficient use of equipment, space and personnel;

(5) Balance the workload of staff, reduce working fatigue, and provide convenient, comfortable and safe working conditions. 


\subsection{System layout design method - SLP}

The system layout design method is a well-organized layout design method which is formed by the application of the system engineering concept and system analysis method to the factory layout by Richard Musset. It combines the logistics analysis with the program analysis of the close relationship between the operation units and seeks the reasonable layout ${ }^{[4]}$. SLP method is first and foremost on the relations between logistics and the logistics operation units, respectively, to establish the relationship between various units table, and according to the comprehensive relational table map rolls in various operational areas connection, this method is not only suitable for all kinds of size or type of factory building, expanding or rebuilding the facilities or equipment in the arrangement or adjustment, is suitable for manufacturing of office and lab, the layout of warehouse design, at the same time, also can be used in the hospital, shop layout design of services ${ }^{[5]}$.

\section{DEPPON EXPRESS WAREHOUSE LAYOUT OPTIMIZATION RESEARCH}

A good functional area relationship is beneficial to reduce the handling distance and minimize the operation time and cost. It can simplify the working process, facilitate the operation, and reduce the problems of cargo blockage, cross currying, accidents and so on between adjacent areas. Benefit the staff to have a safe, reliable and comfortable working environment, greatly reduce the fatigue.

\section{1 logistics relationship analysis}

Table 1: Material flow

\begin{tabular}{|c|c|c|}
\hline $\begin{array}{c}\text { Logistics intensity } \\
\text { level }\end{array}$ & $\begin{array}{c}\text { On behalf } \\
\text { of the } \\
\text { symbol }\end{array}$ & $\begin{array}{c}\text { Undertake the } \\
\text { proportion of } \\
\text { traffic } \%\end{array}$ \\
\hline $\begin{array}{c}\text { Extreme logistics } \\
\text { intensity }\end{array}$ & $\mathrm{A}$ & $30 \%-100 \%$ \\
\hline $\begin{array}{c}\text { High logistics } \\
\text { intensity }\end{array}$ & $\mathrm{E}$ & $20 \%-30 \%$ \\
\hline $\begin{array}{c}\text { Greater logistics } \\
\text { intensity }\end{array}$ & $\mathrm{I}$ & $10 \%-20 \%$ \\
\hline $\begin{array}{c}\text { General logistics } \\
\text { strength }\end{array}$ & $\mathrm{O}$ & $0 \%-5 \%$ \\
\hline Negligible \\
strength
\end{tabular}

As shown in Table 1, in the SLP of system layout and design, each operation unit can be divided into five grades, namely $\mathrm{A}, \mathrm{E}, \mathrm{I}, \mathrm{O}$ and $\mathrm{U}$, according to the proportion of logistics intensity.

Logistics intensity is a basic standard to reflect the close degree of logistics relationship between operating units. It generally refers to the product of the transportation distance of goods and the weight of goods, and its essence is to reflect the quantity of materials between two points. Therefore, the weight of the goods is multiplied by the distance of the goods transported in the warehouse to calculate the logistics intensity.

According to the actual measured data, the logistics intensity results are sorted and graded until the results are shown in Table 2.

Table 2: Scheduling Table of Material Flow

\begin{tabular}{|c|c|c|c|c|c|c|c|}
\hline process & $\begin{array}{c}\text { Through } \\
\text { put }\end{array}$ & $\begin{array}{c}\text { The } \\
\text { proportion }\end{array}$ & level & process & $\begin{array}{c}\text { Through } \\
\text { put }\end{array}$ & $\begin{array}{c}\text { The } \\
\text { proportion }\end{array}$ & level \\
\hline $1 \rightarrow 2$ & 1590 & $10 \%$ & $\mathrm{I}$ & $4 \rightarrow 3$ & 151.2 & $1 \%$ & $\mathrm{U}$ \\
\hline $1 \rightarrow 4$ & 450 & $3 \%$ & $\mathrm{U}$ & $5 \rightarrow 4$ & 12 & $0 \%$ & $\mathrm{U}$ \\
\hline $2 \rightarrow 7$ & 2700 & $17 \%$ & $\mathrm{I}$ & $6 \rightarrow 1$ & 1650 & $10 \%$ & $\mathrm{O}$ \\
\hline $2 \rightarrow 8$ & 1800 & $11 \%$ & $\mathrm{O}$ & $7 \rightarrow 1$ & 3780 & $24 \%$ & $\mathrm{E}$ \\
\hline $2 \rightarrow 9$ & 180 & $1 \%$ & $\mathrm{U}$ & $8 \rightarrow 1$ & 2400 & $15 \%$ & $\mathrm{I}$ \\
\hline $2 \rightarrow 10$ & 10.5 & $0 \%$ & $\mathrm{U}$ & $91 \rightarrow$ & 270 & $2 \%$ & $\mathrm{U}$ \\
\hline $3 \rightarrow 6$ & 900 & $6 \%$ & $\mathrm{U}$ & $10 \rightarrow 1$ & 6.3 & $0 \%$ & $\mathrm{U}$ \\
\hline
\end{tabular}

Note: 1. inlet and outlet, 2. sorting area, 3. packing area, 4. Weighbridge, 5. Packaging material area, 6. Storage area, 7. Logistics area (A), 8. Logistics area (B), 9. Delivery area, 10. Exceptional parts area 


\subsection{Effect after optimization}

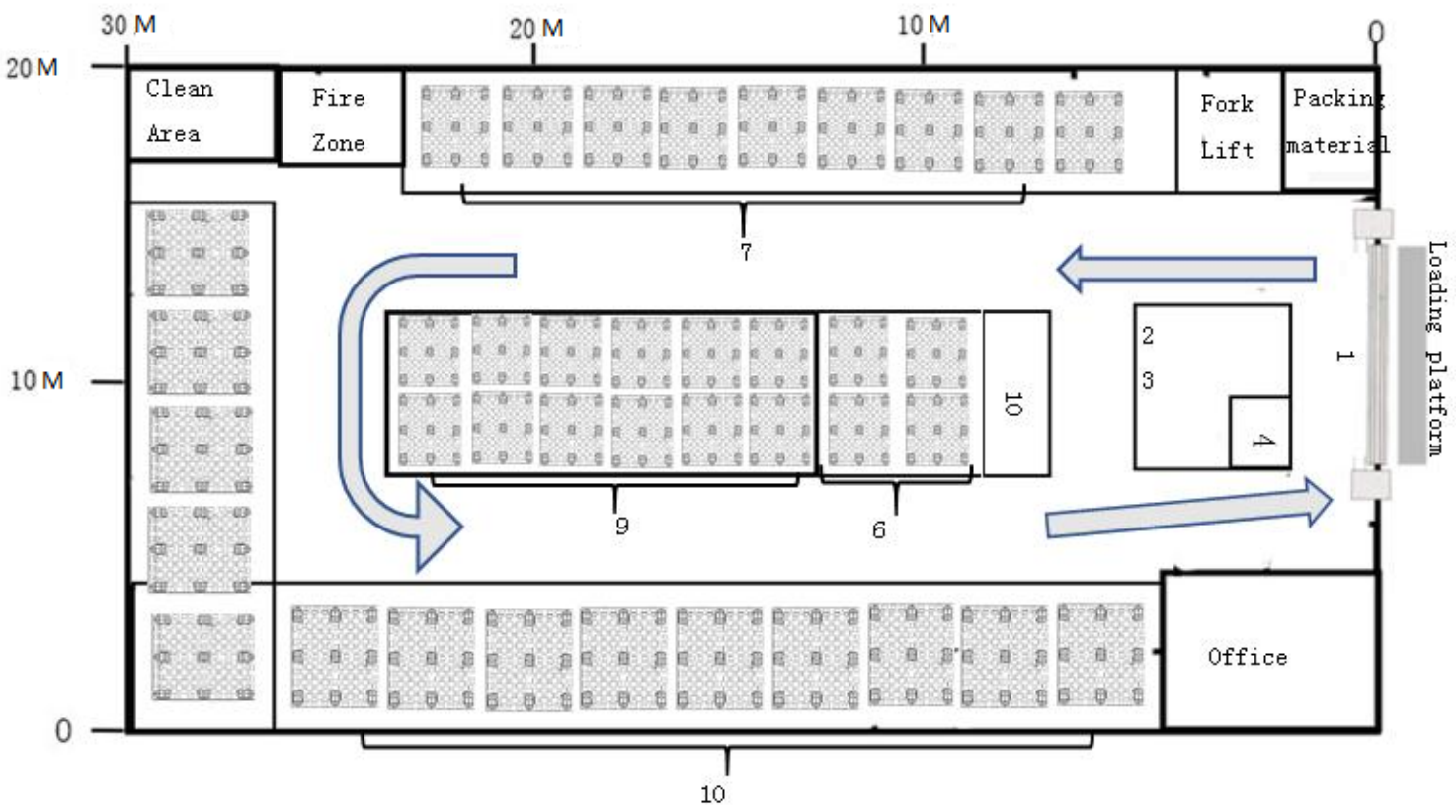

Fig. 1: Optimized effect diagram

Note: 1. inlet and outlet, 2. sorting area, 3. packing area, 4. Weighbridge, 5. Packaging material area, 6. Storage area, 7. Logistics area (A), 8. Logistics area (B), 9. Delivery area, 10. Exceptional parts area

System layout planning and design (SLP) is to determine the comprehensive location and comprehensive relationship according to the degree of comprehensive relationship of the operation area.

The higher the degree, the unit layout is closer to the center of the layout of the center, according to the calculated results, the data show that the warehouse into and out of the port of the comprehensive relationship is the highest, but due to environmental reasons, the warehouse only one gate as the warehouse import and export, the position is fixed cannot be changed. Therefore, the sorting area with the second degree of comprehensive relationship is prioritized as the central location of the layout. The optimized effect diagram is shown in Figure 1.

Secondly, the layout is optimized according to the operation process of the warehouse. On the premise of ensuring the smooth working process, the lower the comprehensive proximity of the operation area is arranged at the edge of the warehouse.

In this optimization, logistics area $\mathrm{A}$ with high inbound and outbound volume and high operation intensity is arranged after the sorting area. Secondly, logistics area A and logistics area B are still close to each other because of the similar operation nature of logistics area $\mathrm{A}$ and logistics area $\mathrm{B}$.

The goods in the warehousing temporary storage area are the goods to be delivered by the customer on the same day, which need to be preliminarily packaged. The packaging material area should be close to the packaging area, so the location of the packaging material area is adjusted to the right of the inlet and outlet, so that there will no longer be more than one round trip when taking packaging materials.
The goods in the abnormal parts area and the warehousing temporary storage area are required to be loaded and transported on the same day to facilitate unified warehousing. The two working areas are merged in one place.

Restricted to the actual situation of the warehouse, there is only one door as the import and export of goods. Before optimization, the goods of the warehouse can only single into single out, and forklifts and other logistics equipment limited mobility, due to the transformation of warehouse, warehouse type belong to the temporary daily goods quantity is big. Therefore, the type of $U$ is accord with the actual requirements.

\section{CONCLUSIONS}

With the development of the national economy, the logistics industry is gradually showing diversified development in order to rapidly occupy the market and meet the needs of customers. The warehouse is not just a single store, standing still, making a difference in time, but moving. Warehousing activities under the new generation is to use the scientific method by means of time and space management, improve the operation efficiency of goods flow, its main performance for the layout of the work unit, the goods in the warehouse loading and unloading time, time, sorting, loading and unloading car goods to fill a cohesion and a series of process flow, so to meet the needs of market competition and development, warehouse cargo area layout optimization is very necessary. In this paper, through the use of SLP, gravels can express warehouse clutter problem, make the goods in the whole process of the movement of the warehouse has more fluency, the 
operation of the staff has more relevance, makes the rolls more see short distances, at the same time reduce the total workload of staff in the warehouse, improve space utilization, has a certain practical significance.

\section{References}

1. Mi Tinglu. Research on Layout Planning of Logistics Park Functional Area Based on Improved SLP [D].Beijing Jiaotong University, 2014.

2. WU Lina, ZHOU Zhili, ZHENG Jiaxin.Analysis and Improvement of Storage Area and Goods Location of a Company $[\mathrm{J}]$. Industrial Engineering and Management, 2006,(04):106-111.
3. $\mathrm{Hu}$ Shaolong, Hu Zhihua, Cao Yang.Research on access path optimization problem based on multiple candidate storage bits [J]. Operations Research and Management, 2013(5)

4. Wang Chenglin, Xue Lili, Wang Qi.Research on storage planning method based on regional association $[\mathrm{J}]$. Logistics Engineering and Management, 2013(6).

5. Wang Yanru, Zhang Baodong.Research on optimization of warehouse layout based on SLP and Craft [J]. Logistics Science and Technology, 2016(11) 